\title{
Framework of human reliability analysis in a geotechnical risk assessment for hillside development
}

\author{
W. P. Nanak \& I. S. H. Harahap \\ Department of Civil Engineering, \\ Universiti Teknologi PETRONAS, Malaysia
}

\begin{abstract}
Limited flat lands in certain developing countries impeded their development progression. To resolve the situation, development projects were extended to hillside areas. Today, landslide cases reported can be closely related with hillside development areas. While landslide is known as a natural hazard, findings have revealed that human error also plays a major role in contributing to landslide events nowadays. Over the years, there is little emphasis or even no concern over the importance of human errors to be considered with landslide related problems in hillside areas. Human Reliability Analysis (HRA) has been applied in other industries to assess the human factors contributing to risks and to facilitate in identifying proper mitigation measures to reduce the risks which can then be proposed to be adopted into the landslide risk assessment. As more and more technological advancement has been introduced to facilitate the complex human activities, the need to focus on the aspects of related human errors is inevitable. As such, human and technological interactions are interrelated in every stage of a project; therefore prompting more errors to be made by humans.

Keywords: landslide, human error, HRA, CREAM.
\end{abstract}

\section{Introduction}

Increasing cases of landslide are closely related to the current trend of urban development in hillside areas. Limited flat lands, increasing size of population and rapid economic growth perhaps further promote urbanization to be encroached to these areas. If the current trend continues, it will result in more hillside areas to be exploited and this will put greater risks to over-development 
in the hillside areas thus induces landslide occurrence in the near future. To resolve the issue, introduction of new policies and procedures or other means of landslide mitigation methods such as restriction of development, using proper construction techniques, use of physical measures e.g. retaining structures, etc. are some of the steps that have been undertaken but despite of their effectiveness as a controlling measures, the continuous reoccurring of landslide problems over the years perhaps raised a lot of question regarding the current approach whether it is reliable in managing the risk of landslide on hillside development. Cruden [1] described landslide as the movement of rocks, debris or earth flowing down a slope. It is commonly triggered by combination of several factors or not less than of the physical and geological elements such as rainfall, earthquake, changes in groundwater, disturbances and change of slope profile. But recent findings revealed that besides these factors, it turns out human error also plays a major role in contributing to landslide. Over the past decades, human errors often been highlighted whenever engineering failures occur but to date, the subject is still yet to be accounted in the current reliability risk-based approach.

The current trend as mentioned earlier also affected Malaysia predominantly at Klang Valley areas. Since the early 90s, the area had succumbed to numerous landslide cases from the infamous collapsed of Tower 1 of Highland Towers in 1993 to the more recent event at Bukit Antarabangsa in 2008. In the span of over 15 years, there are six (6) major cases of landslide recorded within the vicinity of Klang Valley and the aftermath of most cases not limited to property damage and economic losses but also amass numbers of casualties. Table 1 shows the chronology of landslides events in Klang Valley. According to Jamaluddin [2], the causes of many cases of landslides in Malaysia can be related to simplest of human mistakes such as negligence, incompetence, lack or poor maintenance system, ignorance of geological inputs, unethical practice and other various negative human attitudes. His findings also somehow explained the landslide forensic statistical data provided by Slope Engineering Branch where 57\% of landslides were due to human errors, whereas only $29 \%$ and $14 \%$ due to physical and geological factors [3]. Their findings also indicate that most landslides that occurred in Malaysia were mainly took place at man-made slopes which can be linked with the extensive development at the hillside areas.

This study attempts to propose a framework of Human Reliability Analysis (HRA) using Cognitive Reliability and Error Analysis Method (CREAM) to

Table 1: $\quad$ Landslide tragedies in Klang Valley.

\begin{tabular}{|c|c|c|}
\hline Date & Site & Landslide Tragedy \\
\hline $\begin{array}{l}11 \text { December } \\
1993\end{array}$ & Taman Hillview, Hulu Klang, Selangor & $\begin{array}{c}48 \text { people were killed when one block of Highland Towers } \\
\text { Condominium collapsed }\end{array}$ \\
\hline 15 May 1999 & $\begin{array}{l}\text { Bukit Antarabangsa, Hulu Klang, } \\
\text { Selangor }\end{array}$ & Landslide that caused most of the residents trapped. \\
\hline $\begin{array}{l}20 \text { November } \\
2002\end{array}$ & Taman Hillview, Hulu Klang, Selangor & $\begin{array}{c}\text { The collapse of the President of Affin Bank's bungalow, General } \\
\text { Tan Sri Ismail Omar due to the landslide. }\end{array}$ \\
\hline $\begin{array}{l}\text { December } \\
2003\end{array}$ & $\begin{array}{l}\text { New Klang Valley Expressway near the } \\
\text { Bukit Lanjan Interchange. }\end{array}$ & $\begin{array}{l}\text { Rockfall caused the expressway to close for more than six } \\
\text { months. }\end{array}$ \\
\hline 31 May 2006 & Kampung Pasir, Ulu Klang, Selangor. & 4 people were killed in the landslide. \\
\hline $\begin{array}{l}6 \text { December } \\
2008\end{array}$ & $\begin{array}{c}\text { Bukit Antarabangsa, Hulu Klang, } \\
\text { Selangor }\end{array}$ & $\begin{array}{l}5 \text { people were killed in the landslide which buried } 14 \text { bungalows } \\
\text { in Taman Bukit Mewah and Taman Bukit Jaya. }\end{array}$ \\
\hline
\end{tabular}


evaluate the probability of human error in hillside development project. This framework can add more depth or an alternative to the existing practice in geotechnical risk assessment by providing ways to reduce the human related issues in relation with hillside development. The existence of dynamic and multihuman interactions (i.e. planning, design, construction and maintenance stage) made hillside development project a highly complex system. Every stage needs humans to plan, organize, perform and complete an abundance of multiple tasks. Due to the stochastic nature of human behaviour, uncertainties may arise and this vulnerability gives human somehow inevitable to make error at certain point. The issues concerning the human error are no longer new and unfamiliar problems to geotechnical engineering. It is also profoundly distressing to other civil engineering fields such as reported by Ellingwood [4] and Sowers [5] that majority of structural failures were due to the result of the human errors. Bea [6] based on Sowers' findings concludes that the current approach in reliability and risk analyses methods have addressed a very limited part of the challenges posed by uncertainties in geotechnical engineering. The following chapters will discuss the matter pertaining with the impact of human errors to the landslide problems in Malaysia and how Human Reliability Analysis (HRA) can be applied to evaluate the human errors through Cognitive Reliability and Error Analysis Method (CREAM). Bukit Antarabangsa landslide will be used to describe the propose framework in this study.

\section{Landslide and human errors in Malaysia}

Ever since the Highland Tower tragedy in 1993, Klang Valley area has marked with series of landslide cases. This problem prompted several initiatives such as the formation of Slope Engineering Branch under PWD following the Bukit Lanjan rock fall in 2003 and the introduction of Accredited Checkers by the Board of Engineers, Malaysia (BEM) for geotechnical and structural designs of hillside developments. Besides that, numerous studies also conducted to find out the prevalent cause of failures such as statistical data provided by the Slope Engineering Branch. In a study conducted on the 49 cases of mostly large landslides on residual soil slopes, it was found out that $60 \%$ of failed man-made slopes were due to inadequacy in design, $8 \%$ because of failure due to construction errors, about $20 \%$ are caused by a combination of design and construction errors while only $6 \%$ account for geological features and lack of maintenance [7]. In brief, it is understood that most failures were somehow related with human errors as either because of their lack of good understanding, negligence or incompetent in handling engineering design, construction, project supervision or because of their ignorance for details or unethical practice which leads to abuses of prescriptive method e.g. tipping or dumping of loose fill down slopes to form filled platform or filled slope. Communication breakdown amongst involving parties and inability to schedule a periodically maintenance causing lack of monitoring being performed are other forms of human related issues that could further exaggerate the situation. 
Studies of the accidents shows $80 \%$ of the extrinsic factors involved in causation of the major failures mainly involved human, organizational, and knowledge uncertainties. The remaining $20 \%$ of the causation factors involved natural and model related uncertainties. These were identified as Intrinsic factors [6]. This statement defines correctly the situation in Malaysia as most findings suggested that human factors are indeed at large contributing to most landslides. Gertman and Blackman [8] and Hollnagel [9] reported that, regardless of the domain, there seemed to be general agreement that $60-90 \%$ of all system failures could be attributed to erroneous human actions [10]. The causes of landslides can be either because of the action or the consequence of the erroneous action but usually it involves more than one or multiple human errors contribution to trigger the failure. This is understandably correct as what Reason [11] described that many cases of serious events occur because of a combination of unusual conditions and latent human errors that trigger active human errors. Active errors are those that have an immediate effect whereas latent errors are those that do not have an immediate effect but whose consequences can become important at a later time. Example of active errors can be described during the construction stage, where inexperience or new operator excavating a slope surrounded with buildings or other adjacent infrastructures without proper guidance or following proper method can possibly triggers a slope failure. While pipe burst that leads to landslide at Bukit Antarabangsa is an example of latent errors.

\subsection{Anatomy of Bukit Antarabangsa landslide}

The landslide that took place at Bukit Antarabangsa on $6^{\text {th }}$ December, 2008 which caused five (5) casualties, buried fourteen (14) bungalows, and forced about 2000 residents to evacuate their homes shows yet another milestone of numerous tragedies bordering the Klang Valley areas. This is the second time that landslide took place at Bukit Antarabangsa. The landslide is classified as deep seated slide with an estimated of $101,500 \mathrm{~m}^{3}$ of earth had translated with the maximum run out distance of the failure debris was measured at approximately $210 \mathrm{~m}$ from the toe of the slope. This type of landslides moves at a slow rate and cover a short distance. High pore water pressure is the common features associated with this type of failure. There are several factors attributed to the event based on the report of investigation. It is understood that during the event, leaking active pipe running across the slope to the adjacent abandoned house which leads to increase pore water pressure build-up in the slope was found to be the main cause of landslide.

The buried leaked pipe is believed to be damaged by the prolonged soil creep over the years thus caused continuous soil saturation at the non-engineered fill slope which at large consists of non-compacted earth fills. Other factors include abuses of construction methods during development e.g. improper cut and fill method, lack of maintenance, and clogged drains. Generally speaking, if proper maintenance was regularly being performed e.g. clearing the clogged drains; this might prolong the slope from failing. Nevertheless, the failure somehow is unavoidable in an extended time due to the facts that the entire slope is formed with non-compacted or loose soil following the non-engineered fill which took 
place during the early development at construction stage. Stepping aside the rare event i.e. pipe leaked, the root causes of the slope failure can be traced back throughout the entire development stages. Assuming that human attributes as pointed out by Jamaluddin [2] are largely to blame in this case, the probability of human errors can be predicted through application of HRA methods. Figure 1 illustrates a flowchart describing the possible links of the landslide event at Bukit Antarabangsa based on the contributing factors.

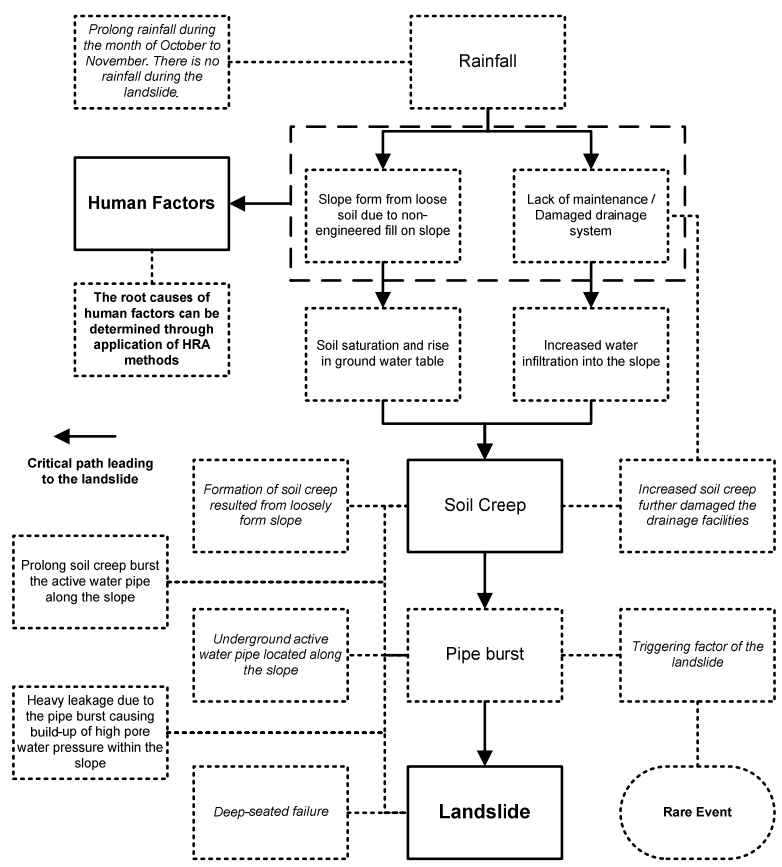

Figure 1: Flowchart of landslide at Bukit Antarabangsa based on the contributing factors that lead to the failure.

\section{Landslide risk assessment and risk management}

Landslide is often described in terms of risk as such of the expected number of lives lost, persons injured, property damaged, or economic activity disrupted because of the event [12]. The term is defined as product of the probability or likelihood of an undesired event and the consequences of that event [13]. It can be assessed qualitatively and quantitatively and the suitability of either assessment depends on both the desired accuracy of the outcome and the nature of the problem, and should be compatible with the quality and quantity of available data [14]. The typical framework of landslide risk assessment and risk management is shown in Figure $2[14,15]$. This paper proposes that human factors can be included within the framework where it can be separately assessed through the use of HRA methods. It is suggests that through the application of 
HRA, the uncertainties of particular human erroneous action during any stages in hillside development projects can be identified by breaking down the tasks within each stage (i.e. planning, design, construction and maintenance). Through that, various available methods of HRA can be applied to quantify both qualitatively and quantitatively to the critical tasks that require human actions to execute.

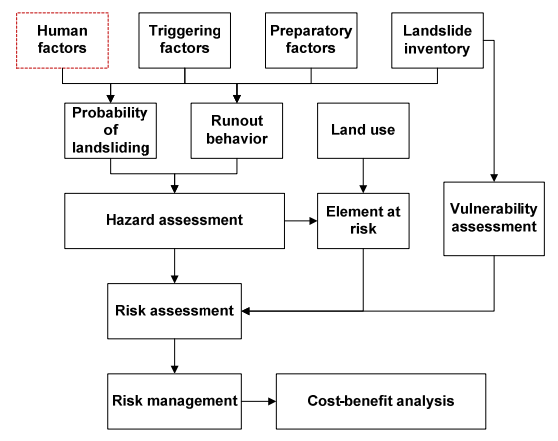

Figure 2: $\quad$ Framework for landslide risk assessment and management [14].

\section{Human reliability analysis}

HRA can be defined as the use of systems engineering and behavioural science methods in order to render a complete description of the human contribution to risk and to identify ways to reduce that risk [16]. The method has been practice since the early 1960s but only in the middle of 1980s that most of HRA methods were developed mainly due to the accident in 1979 at the nuclear power plant at Three Mile Island [9]. Besides primarily applied in nuclear power industry, HRA also has been diverged to other industrial fields such as aviation, medicine, space exploration, etc. The move to include HRA into the current landslide risk assessment could connote a positive turning point in attempt to broaden the current risk-based approaches. Today, as there are a lot of technology advancement were introduced and progressively assimilated to civil engineering fields to feed the ever present of fast track project development, there is danger in injecting more errors.

In socio-technical systems such as hillside development project, human plays a crucial part in performing and executing the lists of tasks presented and with technological tools easing their ways to facilitate their work, human errors can be admitted and spread throughout the system if there is no proper control to minimize the erroneous acts. Some may have immediate effect, some may be embedded and as time passes, will develop and cause failure in the later stage. Although specific rules of thumb may apply in most engineering project, following the rules do not hinder human from committing the erroneous actions. The contexts of human errors are elusive therefore one can arrive with many 
possibilities and uncertainties. The purpose of HRA is to estimate the likelihood of particular human actions (that may prevent hazardous events) not being taken when needed, or other human actions that may cause hazardous events (by themselves or in combination with other conditions) occurring. Failures to take action to prevent hazardous events, and actions that causes hazardous events are commonly called "human errors" in HRA [17]. Table 2 shows three (3) classifications of HRA methods as according to Bell and Holroyd [18].

Table 2: $\quad$ List of HRA methods [18].

\begin{tabular}{|c|c|c|}
\hline & Description & Tool \\
\hline \multirow{3}{*}{$\begin{array}{l}1^{\mathrm{st}} \\
\text { Generation }\end{array}$} & \multirow{3}{*}{$\begin{array}{l}\text { Primarily focus on the skill and rule base } \\
\text { level of human action }\end{array}$} & THERP (Technique for Human Error Rate Prediction) \\
\hline & & HEART (Human Error Assessment and Reduction Technique) \\
\hline & & $\begin{array}{l}\text { SPARH-H (Standardized Plant Analysis Risk - Human } \\
\text { Reliability Analysis) }\end{array}$ \\
\hline \multirow{2}{*}{$\begin{array}{c}2^{\text {nd }} \\
\text { Generation }\end{array}$} & \multirow{2}{*}{$\begin{array}{l}\text { Focus on considering context and errors of } \\
\text { commission in human error prediction }\end{array}$} & ATHEANA (A Technique for Human Error Analysis) \\
\hline & & CREAM (Cognitive Reliability and Error Analysis Method) \\
\hline \multirow{2}{*}{$\begin{array}{l}\text { Expert } \\
\text { Judgment }\end{array}$} & \multirow{2}{*}{$\begin{array}{l}\text { Provide a structured means for experts to } \\
\text { consider how likely an error is in a particular } \\
\text { scenario }\end{array}$} & $\begin{array}{l}\text { SLIM-MAUD (Success Likelihood Index Methodology, Multi- } \\
\text { attribute Utility Decomposition) }\end{array}$ \\
\hline & & APJ (Absolute Probability Judgment) \\
\hline
\end{tabular}

\subsection{Framework of HRA using CREAM for hillside development}

This chapter will discuss the propose framework of HRA to evaluate human errors in hillside development using CREAM. The landslide in Bukit Antarabangsa discussed previously was adopted in this example. CREAM developed by Erik Hollnagel in 1998 is bi-directional analysis method i.e. performance prediction and accident analysis and it is the most widely applied second generation HRA method for the purposes of evaluating the probability of a human error occurring throughout the completion of a specific task. CREAM provides a basic and extended method in quantification approaches. The basic method corresponds to an initial screening of the human interactions. The screening addresses either the task as a whole or major segment of the task. The extended method uses the outcome of the basic method to look at actions or parts of the task where there is a need for further precision and detail [9].

In this paper, only the basic method in CREAM will be discussed. In the Bukit Antarabangsa landslide, the available evidence perhaps put human to be the main perpetrator behind the event with the root causes can be stretched out as far as from the very beginning to later stage of the development. Assuming that human errors are largely to be blamed in this case, the probability of human errors can be predicted through application of CREAM. Figure 3 shows the framework of HRA using CREAM for hillside development. The framework comprises the typical basic structure of HRA where the first half of the framework represented by the steps followed with S1, S2, S3 and S4 indicates the identification of event scenario contexts and associate human actions stage. The main part in this stage is the identification or prediction and assessment of all possible human errors using Fault Tree Analysis (FTA) or Cause and Effect Analysis. Figure 4 shows example of consolidated FTA of maintenance stage based on the event at Bukit Antarabangsa with its description. 


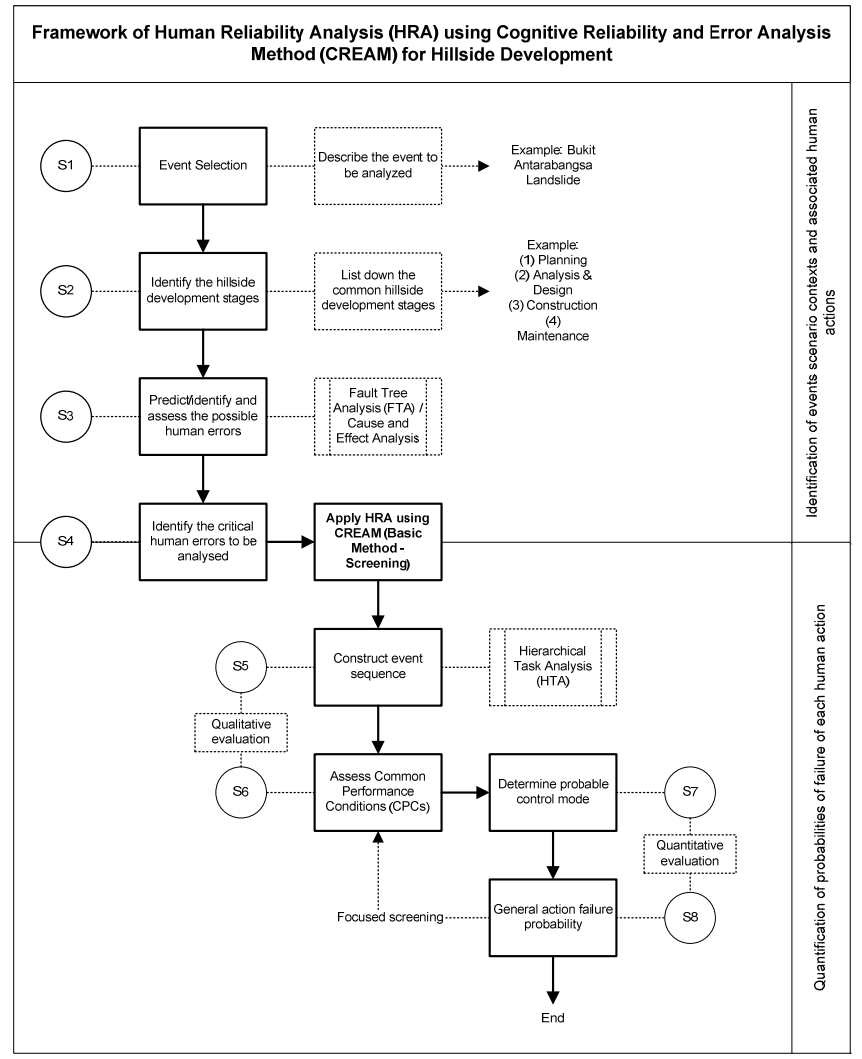

Figure 3: $\quad$ Framework of HRA using CREAM for hillside development.

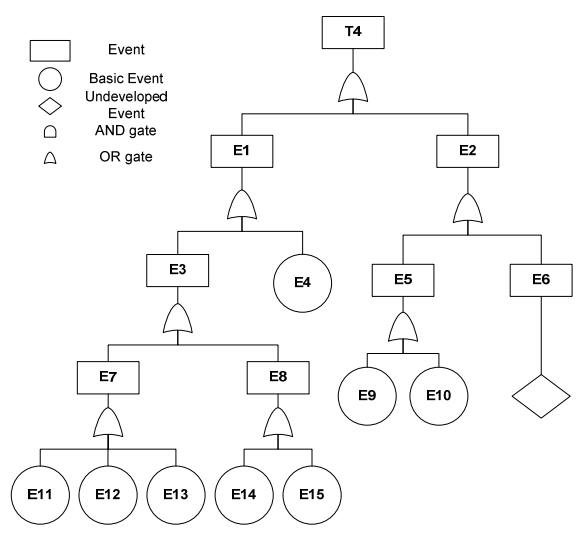

\begin{tabular}{|c|l|}
\hline T4 & Damaged Drainage System \\
\hline E1 & Clogged drains \\
\hline E2 & Inadequate drainage design \\
\hline E3 & Lack of maintenance \\
\hline E4 & Negligence maintenance personnel \\
\hline E5 & Negligence / Inexperience designer \\
\hline E6 & Poorly written / complex design guidelines \\
\hline E7 & $\begin{array}{l}\text { Lack / Inadequate Routine Maintenance } \\
\text { Inspections }\end{array}$ \\
\hline E8 & $\begin{array}{l}\text { Lack / Inadequate Engineer Inspections for } \\
\text { Maintenance }\end{array}$ \\
\hline E9 & Inadequate training \\
\hline E10 & Lack of engineering understanding \\
\hline E11 & $\begin{array}{l}\text { Fail to perform RTI according to specified } \\
\text { schedule }\end{array}$ \\
\hline E12 & Maintenance personnel lack of training \\
\hline E13 & Use of improper work tools \\
\hline E14 & Engineer lack of experience and training \\
\hline E15 & $\begin{array}{l}\text { Poorly documented / complex maintenance } \\
\text { guidelines }\end{array}$ \\
\hline
\end{tabular}

Figure 4: Consolidated FTA of maintenance stage based on the event at Bukit Antarabangsa with its description. 
The result of the FTA can determine the prevailing human errors at each stage. The following half (i.e. S5, S6, S7 and S8) of the framework involves quantification of the probabilities of failure of each human action through the application of CREAM. In the stage, the basic method of CREAM is followed. The first step in the CREAM basic method is to perform task analysis through hierarchical task analysis (HTA). Based on the FTA, assuming event E8, E14 and E15 are to be blamed as the causes of Bukit Antarabangsa landslide. Figure 5 shows the HTA for the task of geotechnical engineer in Engineer Inspection for Maintenance. A list of activities will be produced based on the outcome of HTA. The following step involves an examination and assessment of the work conditions under which the task is performed. The common performance conditions (CPCs) shows in Table 3 are used to characterize the overall nature of the task, and the characterization is expressed by means of a combined CPC score. The combined CPC score can be derived simply by counting the number of times where a CPC is expected: (1) to reduce performance reliability, (2) to

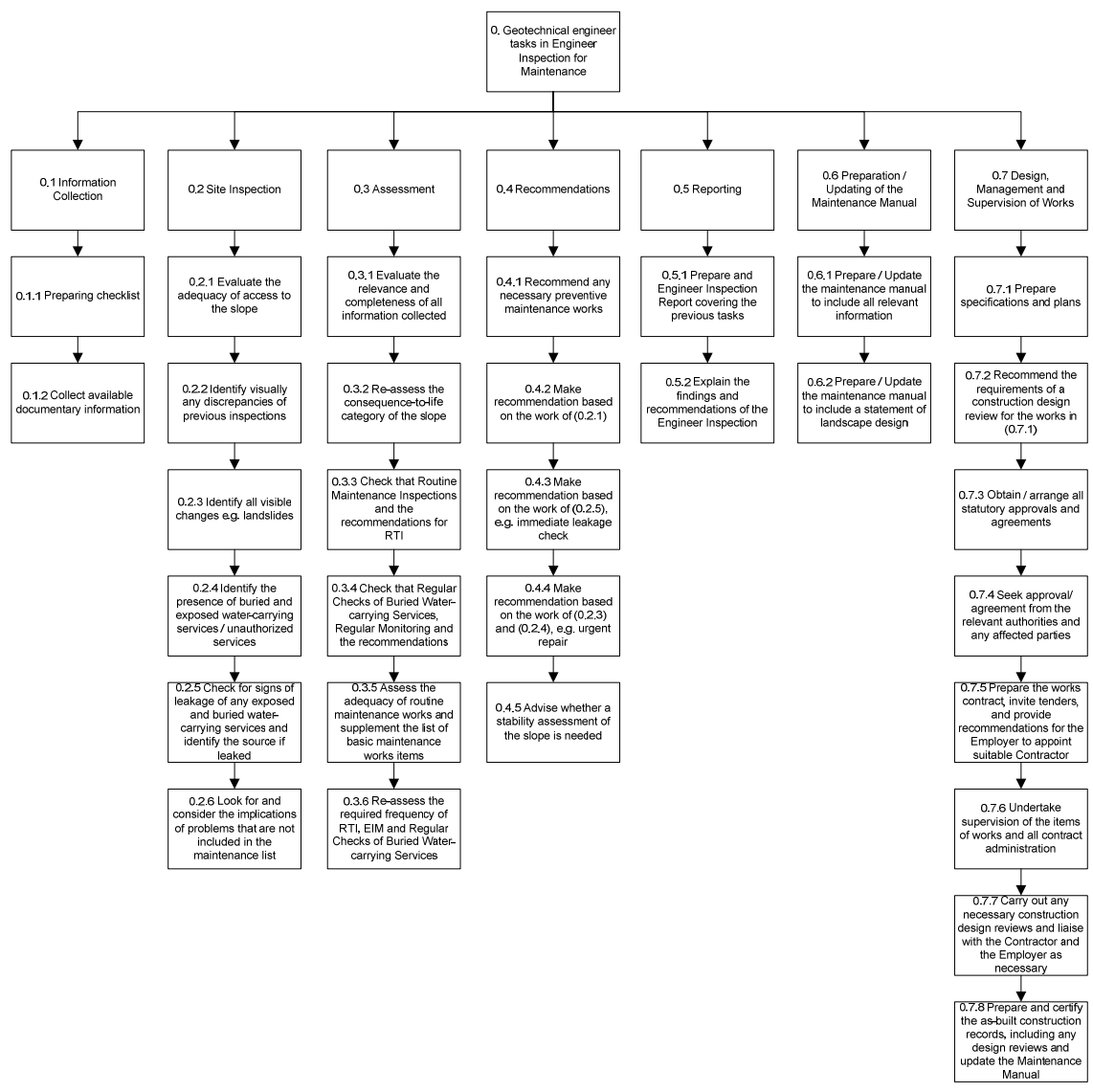

Figure 5: HTA for geotechnical engineer task in Engineer Inspection for Maintenance based on Geoguide [19]. 
Table 3: $\quad$ CPCs and performance reliability [9].

\begin{tabular}{|c|c|c|}
\hline \multirow{2}{*}{ CPC name } & Level / descriptors & $\begin{array}{c}\text { Expected effect on performance } \\
\text { reliability }\end{array}$ \\
\hline \multirow{4}{*}{ Adequacy of organization } & Very efficient & Improved \\
\cline { 2 - 3 } & Efficient & Not significant \\
\cline { 2 - 3 } & Inefficient & Reduced \\
\hline \multirow{3}{*}{ Working conditions } & Deficient & Reduced \\
\cline { 2 - 3 } & Advantageous & Improved \\
\cline { 2 - 3 } Adequacy of MMI and \\
operational support
\end{tabular}

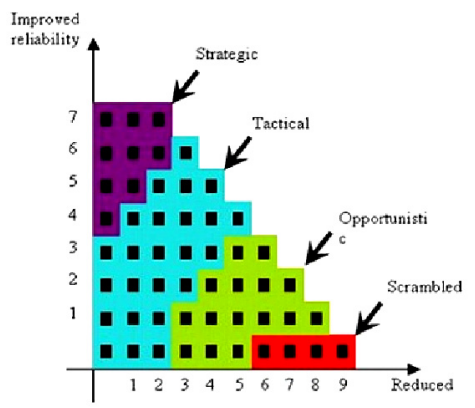

Figure 6: $\quad$ Relations between CPC score and control modes [9].

have no significant effect, and (3) to improve performance reliability. This can be expressed as the triplet $\left[\Sigma_{\text {reduced }}, \Sigma_{\text {not significant, }}, \Sigma_{\text {improved }}\right]$. The final step in the basic CREAM method is to determine the probable control mode and the general action failure probability. Figure 6 is referred to determine the probable control mode and Table 4 will be used to determine the reliability interval for the 
expected control mode. Through this method, it enables an analyst to achieve the following [20]:

1. Identify those parts of the work, as tasks or actions, that require or depend on human cognition, and which therefore may be affected by variations in cognitive reliability.

2. Determine the conditions under which the reliability of cognition may be reduced, and where therefore these tasks or actions may constitute a source of risk.

3. Provide an appraisal of the consequence of human performance on system safety.

4. Develop and specify modifications that improve these conditions, hence serve to increase the reliability of cognition and reduce the risk.

Table 4: $\quad$ Control modes and probability intervals [9].

\begin{tabular}{|c|c|}
\hline Control Mode & Reliability interval (Probability of action failure) \\
\hline Strategic & $0.5 \mathrm{E}-5<\mathrm{p}<1.0 \mathrm{E}-2$ \\
\hline Tactical & $1.0 \mathrm{E}-3<\mathrm{p}<1.0 \mathrm{E}-1$ \\
\hline Opportunistic & $1.0 \mathrm{E}-2<\mathrm{p}<0.5 \mathrm{E}-0$ \\
\hline Scrambled & $1.0 \mathrm{E}-1<\mathrm{p}<1.0 \mathrm{E}-0$ \\
\hline
\end{tabular}

\section{Conclusion}

Although HRA is no longer new to other industries, the concept behind the application of HRA for hillside development is rather new. This paper discusses the current state of landslide in Malaysia where human errors were evidently dubbed as the main perpetrator in most of landslide cases. A framework of HRA using CREAM for hillside development is described and highlighted. With that, it shows that the framework can be used either as performance prediction or as event analysis in identifying parts of works, task or actions, which involve human cognition qualitative evaluation) and determine the reliability of cognition that lead to the source of failure (quantitative evaluation).

\section{References}

[1] Cruden, D. M., A Simple Definition of a Landslide, Bulletin of the International Association of Engineering Geology, 43, 27-29, 1991.

[2] Jamaluddin, T. A., Human Factors and Slope Failures in Malaysia, Bulletin of the Geological Society of Malaysia, 52, 75-84, 2006.

[3] Raya, J. K., Guidelines for Slope Design, Slope Engineering Branch, January 2010.

[4] Ellingwood, B., Design and Construction Error Effect on Structural Reliability, Journal of Structural Engineering, 113(2): 409-422. 1987.

[5] Sowers, G.F., Human Factors in Civil and Geotechnical Engineering Failures, Journal of Geotechnical Engineering, Vol. 119, No. 2: 238-256. 1993. 
[6] Bea, R., Reliability and Human Factors in Geotechnical Engineering, Journal of Geotechnical and Geoenvironmental Engineering, Vol. 132, No 5: 631-643, 2006.

[7] Gue, S. S., Wong S. Y., and Cheah, S. W., Geotechnical Engineering for Hillsite Development, G\&P Geotechnics Sdn Bhd, 2010.

[8] Gertman, D., and Blackman, H. S., Human Reliability and Safety Analysis Handbook, Wiley, 1994.

[9] Hollnagel, E., Cognitive Reliability and Error Analysis Method, Elsevier Science Ltd, 1998.

[10] Forester, J. A., Cooper, S. E., Kolaczkowski, A. M., Bley, D. C., Wreathall J., and Lois, E., An Overview of the Evolution of Human Reliability Analysis in the Context of Probabilistic Risk Assessment, Sandia Report, SAND 2008-5085, January 2009.

[11] Reason, J., Human Error, Cambridge University Press, London. 1990.

[12] Varnes, D.J., Hazard Zonation: A Review of Principal and Practice, Commission of Landslide of IAEG, UNESCO, Natural Hazades, 1984.

[13] Van Staveran, M. Th., Extending to Geotechnical Risk Management, First International Symposium on Geotechnical Safety \& Risk, ISGSR 2007, Oct. 18-19, 2007 Shanghai Tongji University, China.

[14] Dai, F. C., Lee, C. F., and Ngai, Y. Y., Landslide risk assessment and management: an overview, Engineering Geology, 64 (2002) 65-87, 2002.

[15] Ho, K., Leroi, E., and Roberts, B., Keynote Lecture: Quantitative Risk Assessment - Application, Myths and Future Direction, Proceedings of the International Conference on Geotechnical and Geological Engineering, GEOENG 2000, Melbourne, Australia, vol. 1. Technomic, Lancaster, pp. 236-312.

[16] Boring, R., Human Reliability Analysis Methods for Space Safety, RMC, Session G: Human Error and Risk Assessment, Idaho National Laboratory, December 7, 2005.

[17] Wreathall, J., Roth, E., Bley, D., and Multer, J., Human Reliability Analysis in Support of Risk Assessment for Positive Train Control, U.S. Department of Transportation Research and Special Programs Administration John A. Volpe National Transportation System Center Cambridge, MA 02142-1093. 2003.

[18] Bell, J., and Holroyd, J., Review of Human Reliability Assessment Methods, Health and Safety Laboratory Research Report, RR679, 2009.

[19] GEO, Guide to Slope Maintenance: Geoguide 5, Geotechnical Engineering Office, Hong Kong, 2003.

[20] Hollnagel, E., CREAM - Cognitive Reliability and Error Analysis Method, www.ida.liu.se/ eriho/CREAM_M.htm, 2006. 